which also inhibited growth in concentrations of $2 \times 10^{-5} M$ to $5 \times 10^{-4} M$ (Fig. 1), though the effective concentration of salicylate was about twenty times that of $2: 4$-dinitrophenol. The respective concentrations of salicylate and 2:4-dinitrophenol for curtailment of growth are of the same order as for other common effects like inhibition of oxidative phosphorylation by mitochondria and the accompanying increased oxygen consumption by cells, animals and man himself. This finding provides. yet another example of the remarkable similarity in their biological action. It also suggests that the common biological effects of salicylate and $2: 4$ dinitrophenol all emanate from their actions on oxidative phosphorylation.

Clinical Chemotherapeutic Unit

JAMES REID

of the Medical Research Council, Western Infirmary,

Glasgow, W.1. Dec. 18.

${ }^{1}$ Cochran, J. B., Brit. Med. J., ii, 964 (1952).

${ }^{2}$ Alexander, W. D., and Johnson, K. W. M., Clin. Sci., 15, 593 (1956).

${ }^{3}$ Reid, J. (unpublished observation, 1952).

${ }^{4}$ Tenney, S. M., and Miller, R. M., Amer. J. Med., 19, 498 (1955).

${ }^{5}$ Meade, B. W., Ann. Rheum. Dis., 18, 60 (1954).

${ }^{6}$ Sproull, D. H., Brit. J. Pharmacol., 9, 262 (1954).

' Brodie, T. M., J. Pharmacol., 117, 39 (1956).

${ }^{8}$ Lardy, H. A., and Wellman, H., J. Biol. Chem., 195, 215 (1952).

'Simon, E. W., Biol. Rev., 28, 453 (1953).

${ }^{10}$ French, R. C., and Beevers, H., Amer. J. Bot., 40, 660 (1953).

${ }^{11}$ Hancock, C., and Barlow, H. W. B., Rep. East Malling Res. Sta., 88 (1953).

${ }^{12}$ Heath, O. V. S., and Clark, J. E., Nature, 177, 1118 (1956).

\section{A Simple and Safe Procedure for the Removal of Holotrich Ciliates from the Rumen of an Adult Fistulated Sheep}

DURING recent years, increasing attention has been paid to the role of the rumen ciliate protozoa in ruminant nutrition, particularly with regard to the fermentative activity of the holotrich protozoa which contribute to the production of lactic and volatile fatty acids ${ }^{1,2}$. It has, however, become evident that further progress in this direction cannot be made until the contribution of each component species of the rumen microfauna can be studied separately both in vitro and in vivo. Attempts to cultivate the rumen ciliates in vitro have hitherto not met with outstanding success. Gutierrez ${ }^{3}$ managed to separate the two holotrich genera in vitro but only to give a limited yield. The differences in fermentation reactions in vitro found by Gutierrez between Isotricha Stein and Dasytricha Schuberg (cf. Oxford ${ }^{2}$ ) seem to justify attempts to establish single species of holotrichs in vivo unmixed with other species. A method is required which would be as effective as, but less drastic than, the use of prolonged starvation and copper sulphate administration ${ }^{4}$. This objective has so far been reached by us in the one sheep used, to the extent that all three species of holotrichs and the large oligotrichs originally present were removed, leaving only the smaller oligotrich Diplodinium dentatum Stein and a fow Entodinia spp. Following this, Dasytricha ruminantium has successfully been reestablished in the rumen so that fairly large 'pure' samples of this organism in the living state can now be obtained for in vitro studies, by the normal separation process of Heald, Oxford and Sugden ${ }^{5}$.

The method employed was basically to empty the rumen contents from the sheep by way of the rumen canula, to wash out the rumen repeatedly by a method most likely to remove or kill the ciliates and several hours later to return some of the original rumen liquor which had, in the interim, been heated to a temperature which was fatal to the ciliates but not particularly harmful to the bacteria. Direct emptying of the rumen is a routine procedure in physiological experiments ${ }^{6}$ and does not appear to harm the animal.

The sheep was first starved for $48 \mathrm{hr}$. to render the ciliates less active and reduce the solid material in the rumen. The contents were then removed and the first three litres were kept. The rumen was repeatedly washed out first with water and then with 0.9 per cent saline all at $39^{\circ} \mathrm{C}$. Up to 30 litres of washing fluid were used and 4 litres of saline were left in the rumen. Four hours later, washing was repeated and the rumen was then left empty for $1 \frac{1}{2} \mathrm{hr}$. Finally, since the ciliates are very sensitive to hypotonicity, 2 litres of soft tap water were left in the rumen for half an hour before returning the rumen contents. It was hoped that this water would kill any ciliates still present in the rumen, and particularly that it might penetrate to the more inaccessible omasum. The water was present for so short a period that it did not appear to harm the sheep.

The 3 litres of rumen contents had been strained through surgical gauze and were heated in three 1-litre quantities in 2-litre beakers in a waterbath at $50^{\circ} \mathrm{C}$. and maintained at this temperature for 15 min. with constant stirring. After this time no ciliates were found alive. The fluid was then cooled to $38^{\circ} \mathrm{C}$. and maintained at this temperature before being returned to the rumen of the sheep $6 \mathrm{hr}$. after the original emptying.

The sheep, which was carefully isolated from direct contact with other ruminants, was then given access to food and appetite was soon regained. No ciliates were noted until 13 days after the defaunation attempt. As only oligotrich species appeared, the animal was suitable for our purposes; but it is very probable that if the process had been repeated while the population was still small the removal of all ciliate species could have been effected. Dasytricha ruminantium was easily re-established in the rumen some time later by the introduction of about 100 living organisms separated under the microscope from the washed holotrichs from another sheep. At this present date, 11 months after the partial defaunation process had been carried out, $D$. ruminantium is still the only holotrich species present and its population is of the order of $12,000 / \mathrm{ml}$. of rumen contents (cf. Gutierrez $z^{3}$ ). The animal has in the meantime been maintained on good quality meadow hay only and has remained perfectly healthy. The total rumen volatile fatty acid content is about 100 m.equiv. per gm. of wet contents - a perfectly normal figure.

\section{J. Margaret Eadie A. E. OXFORD}

Rowett Research Institute,

Bucksburn, Aberdeenshire. Dec. 5. 'Hungate, R. E., "Biochemistry and Physiology of Protozoa", 2,
edit. by Hutner, S. M., and Lwoff, A. (Academic Press, New York, 1955).

${ }^{2}$ Oxford, A. E., Parasitol. Rev., 4, 569 (1955).

${ }^{3}$ Gutierrez, J., Biochem. J., 60, 516 (1955).

4 Becker, E. R., Schulz, J. A., and Emmerson, M. A., Iowa State Coll. J. Sci., 4, $215(1930)$. ${ }^{5}$ Heald, P. J., Oxford, A. E., and Sugden, B., Nature, 169, 1055

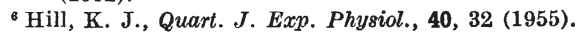

